\title{
GONÇALVES, Marco Antônio. 20I0. Traduzir o outro: etnografia e semelhança. Rio de Janeiro: 7Letras, 172 pp.
}

Erik Petschelies A preocupação principal no mais recente livro de Marco Antônio Gonçalves (UNICAMP) professor do Programa de Pós-Graduação em Sociologia e Antropologia do IFCSUFRJ - é delimitar as condições de possibilidade que fundamentam a antropologia, e mais precisamente a etnografia, como uma forma de compreensão de modos de pensamentos que diferem daquele do próprio antropólogo. Para o autor, os princípios da reflexão antropológica estão calcados em uma epistemologia capaz de relacionar dialogicamente estas visões de mundo diferentes, ao construir analogias entre elas.

Parece que a analogia está no centro da reflexão antropológica por evocar os princípios pelos quais a Antropologia se constrói: alegoria, semelhanças, metáfora e comparação. A Antropologia como método e epistemologia se funda nos mesmos parâmetros que regem o conhecimento estabelecido pela analogia: a capacidade de buscar semelhanças entre coisas diferentes ou desiguais. Assim, o pensamento antropológico é analógico, uma vez que permite tanto ao autor como ao leitor, tanto ao antropólogo quanto ao nativo, a possibilidade de estabelecer semelhança entre as coisas. Neste sentido, a etnografia, vocação da Antropologia, produz um exercício permanente de fazer relação entre pensamentos que são essencialmente diferentes, construindo daí uma espécie de circuito integrado entre as partes (p. 7).

Assim, o antropólogo realiza o trabalho de um tradutor de culturas, buscando estabelecer conexões de significado entre a sua cultura e a do nativo. Na antropologia a questão da diferença e da alteridade como garantia de construção do conhecimento sempre foi enfatizada, ao mesmo tempo em que a analogia é o fundamento da "tradutibilidade" da experiência etnográfica. No entanto, no livro de Gonçalves, a ênfase recai justamente na semelhança, e não na diferença, como princípio dos processos de cognição e inteligibilidade.

Neste sentido, a busca de pontos de correspondência entre mundos conceituais distintos seria, por assim dizer, uma das questões centrais da etnografia. A concepção de tradução que constitui a Antropologia moderna é justamente a possibilidade de produzir semelhanças, articulações, correspondências, o que parece ser, em última instância, o objetivo de toda e qualquer etnografia em cuja construção o antropólogo desempenha o papel de tradutor de mundos para o seu próprio (p. 8). 
Assim sendo, o autor analisa objetos bastante distintos, com o intuito de elevar à categoria de princípio fundamental da epistemologia antropológica a busca por semelhanças interculturais através da tradução cultural do Outro. O livro divide-se em duas partes, "Analogia e Escrita Etnográfica" e "Analogia e Pensamento Ameríndio", em que são apresentados os ensaios do autor, todos anteriormente publicados em revistas ou apresentados em congressos. Na primeira parte Gonçalves procura inventariar a analogia na escrita etnográfica, selecionando objetos em que a constituição da etnografia fosse também uma preocupação dela mesma, ou seja, como metalinguagem. $\mathrm{Na}$ segunda parte, ele realiza uma reflexão acerca de sua própria etnografia, com o intuito de situar os conceitos de semelhança, diferença e tradução nos seus escritos, fazendo uma analogia com os conceitos indígenas.

O livro inicia-se ao explorar o conceito de tradução nas primeiras etnografias realizadas no Brasil através das expedições científicas no final do século XIX, lideradas por Karl von den Steinen, Adolf Bastian, Theodor KochGrünberg, Max Schmidt, Paul Ehrenreich, Fritz Krause, Hermann Meyer e Karl Ranke. As etnografias resultantes destas expedições, somada à influência de Franz Boas, estabeleceram como princípio a escrita etnográfica como forma de estabelecer correspondências, em que a tradução não apenas cria o contexto de semelhança, mas também realiza a compreensão. Nestas obras, em que a escrita do Outro era realizada pela "fraseologia" (uma tradução linear e morfêmica da fala nativa) a língua era concebida como a forma de acesso a uma visão de mundo singular. Com base nestes preceitos, o historiador Capistrano de Abreu escreveu uma etnografia sobre os Kaxinauá que apresentava simultaneamente uma forma (língua/gramática) e um conteúdo (cultura/pensamento) da narrativa indígena, denominada por ele de "etnografia selvagem". Assim, ao reunir 5.926 frases colhidas por informantes (coautores do livro) indígenas no Rio de Janeiro e traduzi-las literalmente, Capistrano de Abreu buscou realizar uma etnografia que diferisse substancialmente daquela inspirada nas crônicas dos viajantes, praticada por Bronislaw Malinowski e seus discípulos. Após a tradução, segue-se uma interpretação das frases, intercalada com depoimentos dos índios, culminando em uma etnografia que buscou captar a cultura como ela aparecia para o próprio índio.

No capítulo seguinte, Gonçalves se concentra na etnografia de Raymond Firth, Nós, os Tikopias, uma vez que para o autor, este livro estabeleceu na Antropologia uma preocupação fundamental em relação ao estilo etnográfico e ao lugar da experiência na própria obra. Ao situar a própria subjetividade na relação com os nativos, Firth inaugura um princípio de correspondência entre o pensamento nativo e o do antropólogo. Isso significa que a descrição extremamente detalhada de todos os aspectos da vida social dos Tikopia revela uma epistemologia etnográfica, para a qual a etnografia é um meio de estabelecer conexões de significado entre os nativos, o autor e o leitor ao construir uma narrativa e interpretação a respeito dos próprios modos de conhecimento. A descrição tem um peso importante na obra de Firth, pois através dela ele reflete sobre o que um fato e o que é uma interpretação. Para Gonçalves (p. 55), “Firth parecia defender a ideia de que somente o etnógrafo, aquele que faz a pesquisa, é quem sabe distinguir um fato de uma interpretação, e nesse sentido, as reinterpretações dos 'fatos' por outras pessoas são apenas possíveis quando se assume explicitamente o caráter interpretativo de tal empreendimento". Isso significa que o mimetismo etnográfico de Firth tem como objetivo, aliado à subjetividade como modo de conhecimento, o compartilhamento da experiência, através da escrita. De fato, não apenas a epistemologia etnográfica de Firth 
difere dos estudos de sua época, como também a apreensão que faz a cultura. Ao invés de analisar as funções sociais dos eventos e de se concentrar na estrutura social, Firth trata os aspectos da vida social como fenômenos que interligam, e a partir disso emerge a estrutura. Neste sentido, o autor valoriza as categorias nativas enquanto produtoras de significado, justificando o seu método descritivo. Dessa forma, para Gonçalves, Firth realiza um dos preceitos da Antropologia, o de encontrar as semelhanças nas diferenças, através da tradução da cultura.

Justamente a noção de cultura, tal como problematizada por Roy Wagner - a partir de sua etnografia Habu. The innovation of meaning in Daribi religion (1972) - é o tema do terceiro capítulo, o último da primeira parte. Além disso, este capítulo se constitui como um exercício de compreensão de outros conceitos esboçados por Wagner, como metáfora e representação, e, por fim, aponta de forma interessante semelhanças e diferenças entre a abordagem de Wagner e de Clifford Geertz e Marshall Sahlins no que diz respeito ao conceito de cultura. Gonçalves aponta que Wagner foi profundamente influenciado pela Antropologia Simbólica (também chamada de Cognitiva), que "valorizava o discurso nativo observando a construção de sua lógica, enfatizando a importância dos seus significados ao mesmo tempo em que problematizava o conhecimento da Antropologia enquanto detentora da função de representação desse pensamento nativo" (p. 74). Embora a compreensão da lógica nativa e a sua consequente elevação a uma categoria não seja exclusividade da Antropologia Simbólica, inaugurou-se um estabelecimentos de conexões de significados entre a conceituação nativa e a dos antropólogos, não por meio da descrição da experiência como mostrado em Firth, mas pela existência de ordenamentos lógicos comuns a todos os tipos de representação e apreensão, pois isso ocorre justamente na ordem da metáfora e dos significados. Wagner então demonstra que a invenção metafórica é intrínseca às culturas, que não são ordenações lógicas inexoráveis. Isso ocorre porque "o significado criado pela formação de metáforas envolve os elementos formais de uma cultura, e as relações entre metáforas dentro de uma cultura podem ser complementares (consistência) ou de inovação (contradição)" (p. 79). Dessa forma, a ideia fundamental de Wagner é que a cultura está em um processo permanente de criação e inovação, o que significa que a transformação cultural está no cerne da própria cultura. Precisamente a mudança cultural é o aspecto que liga e afasta Wagner de Sahlins. Segundo este, toda cultura, em sua tentativa de compreender os eventos, contextualiza-os, e como resultado ocorre um rearranjo na sua estrutura cultural. Os eventos são exteriores à cultura e como ações são signos reinterpretados gerando uma mudança cultural. Já Wagner localiza o problema na antinomia entre ação e pensamento: o evento é produto da estrutura e a metáfora é a formulação do evento. Esta antinomia também o difere de Geertz, para quem a etnografia é calcada nas ações e deve ser participativa. Ela é a forma privilegiada para o entendimento da cultura, entendida como um sistema de símbolos, que precisa ser entendida em seus próprios termos. Para Wagner as ações sociais são metaforizações das regras sociais, o que implica em relacionar através da ação ou do pensamento. Enquanto Geertz valoriza as ações em detrimento ao pensamento, Wagner coloca-os no mesmo patamar.

Seguindo a linha proposta pela Antropologia Simbólica e por Wagner, no quarto capítulo, o primeiro da segunda parte, Gonçalves busca compreender de que forma a "cultura" (com aspas, lembrando o termo cunhado por Manuela Carneiro da Cunha, com quem o autor não dialoga explicitamente) se torna um conceito nativo. Entretanto, 
o autor afirma que as relações não apenas inventam novas tradições, mas também realizam articulações. Neste sentido, Gonçalves relata que nos anos 80 os Pareci (grupo indígena do Mato Grosso) produziam artesanato para vendê-lo a quem passava pela rodovia BR-364 que cortava a Reserva Indígena. Este artesanato se caracterizava por ser uma criação livre Pareci do tema do índio genérico. O autor afirma que "para os Pareci era claramente uma invenção, nunca venderam os artefatos como sendo peças tradicionais de sua cultura, nunca enfatizaram esse aspecto, eram 'souvenir' de índio" (p. 91). No entanto, após uma série de acontecimentos que culminaram em uma autorreflexão Pareci, como a Eco-92 e tentativa de instalação de um museu em uma das aldeias, o artesanato tornouse símbolo de uma representação de distintividade dos Pareci em relação aos outros povos indígenas. Gonçalves relata que em uma visita que dois Pareci lhe fizeram no Rio de Janeiro, levou-os ao Museu Nacional, onde viram as flautas mágicas, que segundo eles, Ihes foram roubadas e levadas à época de Cândido Rondon. $O$ encontro com as flautas mágicas inverte exatamente a fórmula postulada por Sahlins, de que a cultura não é um objeto que pode ser perdido. Segundo Gonçalves, "parece que cultura se tornou literalmente um bem, algo materializável, que pode ser trocado, representado, essencializado independente de qualquer forma de interação social. E enquanto se tem a posse desse bem, ele não pode ser perdido" (p. 103). Em outras palavras, os índios Pareci, a partir da relação com a noção de cultura pregada por antropólogos e outros brancos, realizaram uma reflexão eles mesmos sobre o que isso significa, e a conclusão a que chegaram difere do conceito inicial.

O quinto capítulo do livro versa sobre as qualidades simultâneas imanentes à constituição da identidade de André Fernando, personagem central de um filme sobre os Baniwa (povo Aruak que habita a fronteira do Brasil com a Colômbia e Venezuela), Koame wemakaa pandza kome watapetaaka kaawa - Baniwa, uma história de plantas e cura. Estas não condizem com o modo ocidental, de rotular como contraditórias certas características de identidades baseadas em modos de pensar diferentes. André Fernando é evangélico, conhecedor do catolicismo, intérprete da cosmologia Baniwa, empresário e liderança indígena. A interpretação da relação de André Fernando com o sobrenatural e a cura de doenças ajuda a refletir sobre a condição que os índios se encontram no Brasil, sobretudo no que diz respeito ao diálogo com a sociedade nacional. André Fernando é quem sintetiza o modo pelo qual as características podem coexistir sem conflitos: "a partir do catolicismo, do evangelismo e da tradição Baniwa pode surgir uma coisa diferente" (p. 111). Novamente Gonçalves mostra a maneira como os índios refletem a respeito da sua própria cultura e da cultura da sociedade nacional (representadas neste caso através das religiões mundiais), recriando significados e estabelecendo conexões significativas baseadas em correlações semânticas sujeitas a interpretações variadas - o que, entretanto, não deve ser caracterizado como ambiguidade lógica.

Os dois últimos capítulos versam sobre a complexa cosmologia Pirahã (povo de língua Mura que habita a Amazônia), primeiramente, ao demonstrar a importância da semelhança no pensamento cromático indígena e em seguida como modo de subjetivação ontológica. Nestes dois capítulos Gonçalves estende a sua reflexão - antes localizada na própria escrita etnográfica e depois na reflexão e invenção indígenas de conceitos alienígenas - para a importância de algumas noções indígenas e o modo como estas são fundamentais para a sua compreensão de mundo. O capítulo sexto trata, portanto, da noção Pirahã igiábisai, utilizada na construção semântica e classificação 
das coisas (humanos, animais, seres sobrenaturais) existentes no cosmos, relacionando os seres pelas suas semelhanças, mas preservando as suas diferenças: tudo se parece, mas nada é igual. Esta forma de pensamento, afirma o autor, remete à noção de cromatismo, desenvolvida por Claude Lévi-Strauss, segundo a qual o pensamento indígena operaria através de uma alternância dialética entre grandes e pequenos intervalos, operando a diferença através da contiguidade e da semelhança. Recuperando concepções de outros grupos indígenas sobre modificadores cosmológicos e suas operações com o binômio semelhança-diferença, o autor afirma que se pode pensar o universo mitológico ameríndio como constituído por relações de transformação. A questão da continuidade e da ruptura é revelada também pela ideia indígena da alteridade, que, ao invés de ser pensada como uma oposição, é constituída através da relação de complementaridade. Portanto, "a alteridade não se constrói por pares de oposição em que o eu estaria em oposição a um outro, mas, de fato, o eu se constrói e depende do não-eu, e não do outro como figura ontológica de alteridade para constituir a diferença" (p. 132). Em outras palavras, do sistema de diferenças emerge o pensamento e que se manifesta em suas mais diversas formas.

O sétimo capítulo trata justamente dos processos de individuação e singularidade entes os Pirahã, e de que forma se constrói na relação com o outro uma noção de pessoa. Gonçalves faz uma genealogia da noção de indivíduo e de coletividade na antropologia (Émile Durkheim, Marcel Mauss, Louis Dumont, Marilyn Strathern e Joanna Overing) para se valer de uma conceituação que valoriza a experiência pessoal como discurso sobre a cultura. Segundo ele, "pode-se pensar a pessoalidade enquanto uma construção de subjetivação singular de experiências, de momentos que não se repetem e cuja interação e pensamento sobre o social se realizam por e através da forma de subjetivar essa pessoalidade" (p. 143). Assim sendo, Gonçalves analisa diversas categorias Pirahã -ibiisi, abaisi, kaoaiboge e toipe - demonstrando a fusão entre indivíduo e classe, os resultados das transformações corporais cosmológicas e as relações entre semelhança e diferença, com o intuito de caracterizar a noção de pessoalidade entre os Pirahã - mas também de contribuir para uma reflexão antropológica acerca dos conceitos de indivíduo e sociedade.

Assim Marco Antonio Gonçalves fecha um ciclo. Ele inicia o livro com uma reflexão sobre as condições de possibilidade do fazer etnográfico, calcado tanto na diferença como modo de produção do conhecimento, quanto na semelhança como forma de compreensão mútua, e o finaliza sublinhando a importância das noções de alteridade e semelhança nas cosmologias indígenas (além de uma análise das cosmologias em si). Ocorre assim um diálogo constante com as filosofias indígenas: o antropólogo reflete sobre as culturas dos índios, que refletem sobre a cultura do antropólogo e sobre as suas próprias. Assim, na medida em que a cultura do antropólogo serve de estímulo para a reflexão dos índios sobre a sua própria cultura, a cultura dos índios serve de estímulo para pensar o fazer etnográfico e os conceitos mobilizados pela antropologia.

Erik Petschelies é mestrando do Programa de Pós-Graduação de Antropologia Social da Unicamp 